Article

\title{
Zirconium triflate grafted on SBA-15 as a highly efficient solid acid catalyst for ring opening of epoxides by amines and alcohols
}

\author{
Kamlesh N. Tayade a, Lianyue Wang a, Sensen Shang a, Wen Dai a, Manish Mishra b, Shuang Gao a,* \\ a Dalian National Laboratory for Clean Energy, Dalian Institute of Chemical Physics, Chinese Academy of Sciences, Dalian 116023, Liaoning, China \\ b Department of Chemical Engineering And Shah-Schulman Center for Surface Science and Nanotechnology, Faculty of Technology, Dharmsinh Desai \\ University, Nadiad 387001, Gujarat, India
}

\section{A R T I C L E I N F O}

\section{Article history:}

Received 21 November 2016

Accepted 6 January 2017

Published 5 April 2017

\section{Keywords:}

Epoxide ring opening

Acid catalysis

Metal triflate

Grafted catalyst

Mesoporous silica

\begin{abstract}
A B S T R A C T
Metal (Al, Ti, Zr) triflate grafted mesoporous SBA-15 (AlTf/S, TiTf/S, ZrTf/S) samples were synthesized as inexpensive solid acid materials by a simple one-pot-two-step synthesis methodology. These materials were characterized by X-ray diffraction, $\mathrm{N}_{2}$-sorption, thermogravimetric analysis, Fourier transform infrared spectroscopy (FT-IR), in-situ pyridine FT-IR spectroscopy, and elemental analysis. ZrTf/S was found to be a highly efficient and reusable solid acid catalyst for ring opening of epoxides with amines and alcohols and produced $\beta$-amino alcohols and $\beta$-alkoxy alcohols respectively under ambient reaction conditions. The ZrTf/S catalyst showed the highest activity, which was attributed to its high acidity compared with that of the Ti and Al containing samples.
\end{abstract}

(C) 2017, Dalian Institute of Chemical Physics, Chinese Academy of Sciences. Published by Elsevier B.V. All rights reserved.

\section{Introduction}

Ring opening of epoxides is an important transformation in organic synthesis because it provides access to valuable pharmaceuticals and intermediate chemicals [1-5]. Bifunctional molecules of great significance can be synthesized by nucleophilic attack of amines, azides, alcohols, and thiols on epoxide rings. For example, $\beta$-alkoxy alcohols are used as intermediates for the synthesis of pharmaceutical compounds, such as antitumor and immunosuppressant drugs [6]. $\beta$-Amino alcohols are used for synthesizing $\beta$-blockers, insecticidal agents, unnatural amino acids, chiral auxiliaries and oxazolines [2-5].

Several studies have reported the synthesis of $\beta$-amino alcohols and $\beta$-alkoxy alcohols by aminolysis and alcoholysis of epoxides, respectively, using homogeneous and heterogeneous acid catalysts. However, homogeneous catalytic processes are unattractive considering their disadvantages, such as the use of halogenated and/or toxic solvents and the difficultly of separation and poor reusability of the catalyst. Solid acid catalysts, such as sulfonic acid functionalized SBA-15 and Ti-MCM-41 [7], Na-Y zeolite [8], Cu-MOF (Cu(bpy) $\left.\left(\mathrm{H}_{2} \mathrm{O}\right)_{2}\left(\mathrm{BF}_{4}\right)_{2}(\mathrm{bpy})\right)$ [9], mesoporous alumininosilicate [10], $\mathrm{Fe}(\mathrm{BTC})$ (where BTC is 1,3,5-benzenetricarboxylate) [11], $\mathrm{CuO} / \mathrm{SiO}_{2}$ [12], Ti-SBA-12 and Ti-SBA-16 [13], sulfonic acid functionalized mesoporous carbon [14], graphite oxide [15], and mesoporous Zr-beta zeolite [16], have been shown to be active and selective for ring opening reactions of epoxides. However, these catalysts also have some limitations, such as the need for longer reaction times [7-15] and non-ambient reaction conditions [11,12,14], and tedious synthesis of the catalyst $[7,16]$. Therefore, the development of easy to synthesize, more efficient and environmentally benign catalysts is of great importance.

\footnotetext{
* Corresponding author. Tel/Fax: +86-411-84379728; E-mail: sgao@dicp.ac.cn

This work was supported by the CAS President's International Fellowship Initiative (2016PT028) and the National Natural Science Foundation of China (21273225 and 21403219).

DOI: 10.1016/S1872-2067(17)62794-3| http://www.sciencedirect.com/science/journal/18722067 | Chin. J. Catal., Vol. 38, No. 4, April 2017
} 
Metal triflates (especially triflates of lanthanides and transition metals) have received considerable attention as excellent Lewis acid catalysts for several organic reactions over the past two decades [17-22]. Consequently, supported metal triflates have also been synthesized and used for important acid-catalyzed reactions allowing easy separation, good reusability and enhanced activity [23-30]. It is generally preferable for the catalyst to be chemically grafted to rather than physically adsorbed to the support because of the greater stability of chemically grafted systems. In our previous reports, we developed an aluminum triflate grafted on MCM-41 as a cost effective and easily synthesizable catalyst, which showed high acidity and water tolerance in ketalization of glycerol with acetone into solketal at room temperature [31]. In the present work, metal triflates of $\mathrm{Al}, \mathrm{Zr}$, and Ti grafted on SBA-15 mesoporous silica (AlTf/S, TiTf/S, and ZrTf/S, respectively) were prepared. We aimed to generalize our one-pot-two-step synthesis methodology and widening the applications of metal triflate grafted catalysts to epoxide ring opening reactions as a more efficient, low cost and environmentally benign catalyst system. SBA-15 mesoporous silica was chosen as the support owing to its high pore size, thick framework walls and good hydrothermal stability and inter-channel connectivity [32].

\section{Experimental}

\subsection{Materials}

Pluronic P123 (PEO-PPO-PEO) polymer was purchased from Sigma. Zirconium propoxide $(70 \%)$ in propanol was procured form Alfa-Aesar. Tetraethyl orthosilicate (TEOS), $\mathrm{HCl}$ (35\%), titanium tetraisopropoxide, aluminum isopropoxide, all epoxides, amines and alcohols were purchased from Sinopharm Chemical Reagents Co. Ltd, Energy Chemical and J \& K Scientific, China. All the chemicals were used as received without any purification.

\subsection{Synthesis of metal triflate grafted SBA-15 samples}

Mesoporous silica SBA-15 was prepared by a reported method using pluronic P123 polymer as template under acidic conditions. Typically, $4 \mathrm{~g}$ of P123 was dissolved in $30 \mathrm{~mL}$ water and $90 \mathrm{~mL}$ of $\mathrm{HCl}$ solution ( $2 \mathrm{~mol} / \mathrm{L})$. TEOS was added dropwise with stirring to the polymer solution and allowed to stir at room temperature for $15 \mathrm{~min}$. The mixture was then aged at 40
${ }^{\circ} \mathrm{C}$ for $20 \mathrm{~h}$. The gel produced was transferred to a Teflon-lined stainless steel autoclave and maintained at $80^{\circ} \mathrm{C}$ for $2 \mathrm{~d}$ for the hydrothermal synthesis. After $2 \mathrm{~d}$, a white solid formed which was filtered, washed with distilled water and then dried at 100 ${ }^{\circ} \mathrm{C}$ overnight. The dry solid powder was then calcined at $550{ }^{\circ} \mathrm{C}$ for $4 \mathrm{~h}$ under an air flow to remove the template and obtain the final SBA-15 material.

Trifluoromethane sulfonic acid (0.1 g) was dissolved in 25 $\mathrm{mL}$ of toluene. This solution was added to a solution containing zirconium propoxide (70\% in propanol; $0.2951 \mathrm{~g}$ ) dissolved in $25 \mathrm{~mL}$ of toluene and allowed to react for $2 \mathrm{~h}$ at r.t. under stirring. Dried SBA- $15\left(150{ }^{\circ} \mathrm{C}\right.$ for $\left.4 \mathrm{~h}, 1 \mathrm{~g}\right)$ was then added to this solution and allowed to react for $24 \mathrm{~h}$ at r.t. The solid was then filtered and washed with toluene and dichloromethane/acetonitrile $(v / v=1)$. The solid powder was then dried at $100{ }^{\circ} \mathrm{C}$ for $24 \mathrm{~h}$ to obtain zirconium triflate grafted on SBA-15 (ZrTf/S) samples. Titanium isopropoxide (0.1895 g) and aluminum isopropoxide $(0.1362 \mathrm{~g}$ ) were used to prepare the titanium and aluminum triflate grafted SBA-15 (TiTf/S and AlTf/S) samples in a similar manner. The metal/Si molar ratio was maintained at $1 / 25$ for all sample preparations. A schematic representation of the ZrTf/S synthesis is shown in Scheme 1. The synthesized catalyst samples were used for aminolysis and alcoholysis of various epoxides by amines and alcohols, respectively (Scheme 2).

\subsection{Material characterization}

Mesoporous SBA-15 and the samples ZrTf/S, TiTf/S and AlTf/S were characterized with the following analytical techniques. Powder X-ray diffraction (XRD) analysis was performed on a PANalytical X'Pert3 powder diffractometer with $\mathrm{Cu} K_{\alpha}$ radiation $(\lambda=1.5418 \AA ; 1 \AA=0.1 \mathrm{~nm})$ in the $2 \theta$ range of $0.5^{\circ}$ to $10^{\circ}$ with a scanning rate of $0.02^{\circ} / \mathrm{s}$. The $\mathrm{N}_{2}$ sorption at liquid nitrogen temperature $\left(-196^{\circ} \mathrm{C}\right)$ for determination of pore size and pore volume, and the BET surface area measurements were performed on a Quantachrome Quadrasorb SI. The samples were degassed at $180^{\circ} \mathrm{C}$ for $4 \mathrm{~h}$ before the measurements. The C, H, S elemental analysis was performed with a VarioEL elemental analyzer. Metal content was determined by inductively coupled plasma atomic emission spectroscopy (ICP-AES) with a PerkinElmer OPTIMA 3300DV. A sample (50 mg) was dissolved in $40 \%$ HF solution (5-10 drops) followed by addition of a $5 \mathrm{wt} \%$ boric acid solution and made up to $100 \mathrm{~mL}$ in a volumetric flask. The resulting solutions were then analyzed by

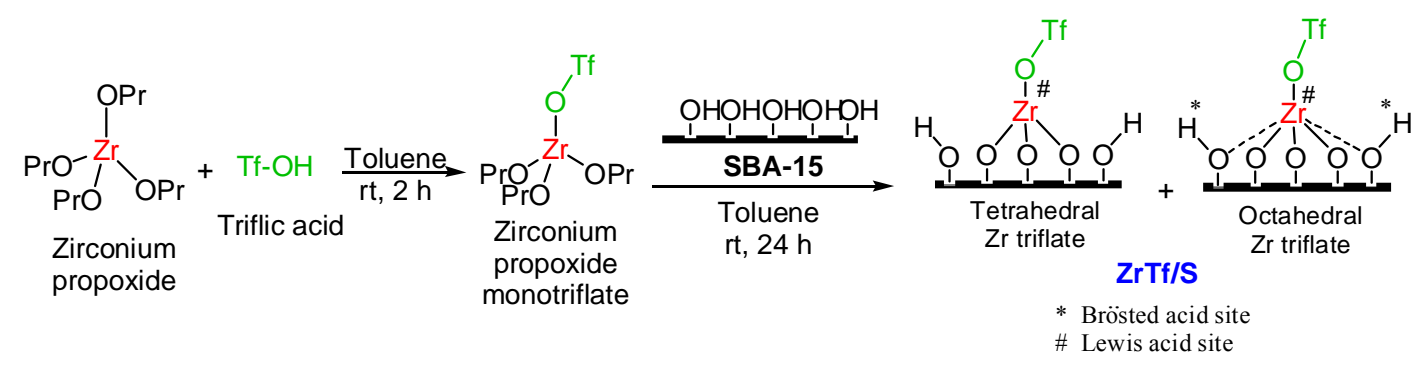

Scheme 1. One-pot-two-step synthesis of ZrTf/S and diagram of the Brönsted (B) and Lewis (L) acid sites in the ZrTf/S sample. 


$$
\begin{aligned}
& \text { Emine } \\
& \text { Epoxide }
\end{aligned}
$$

Scheme 2. Ring opening of epoxides by amines and alcohols to synthesis $\beta$-amino alcohols and $\beta$-alkoxy alcohols.

ICP-AES. Thermogravimetric analysis (TGA) was performed with a NETZSCH STA 449 F3 Jupiter under an air flow of 50 $\mathrm{mL} / \mathrm{min}$ from 40 to $800{ }^{\circ} \mathrm{C}$. Diffuse reflectance UV-visible spectroscopy was performed with a PerkinElmer LAMBDA 950 UV/Vis/NIR spectrophotometer at r.t.; samples were activated at $100{ }^{\circ} \mathrm{C}$ for $1 \mathrm{~h}$ prior to the analysis. Fourier transform infrared (FT-IR) spectroscopy was performed with a Thermo Nicolet iS50 FT-IR spectrometer. In-situ FT-IR under vacuum with pyridine-adsorbed and pyridine-desorbed samples at different temperatures was performed with a Bruker TENSOR27 instrument. A neat sample disk was evacuated at $10^{-2} \mathrm{~Pa}$ at 200 ${ }^{\circ} \mathrm{C}$ for $1 \mathrm{~h}$ followed by pyridine adsorption for $5 \mathrm{~min}$. FT-IR spectra were then recorded after desorbing pyridine at 100 , 150 , and $200{ }^{\circ} \mathrm{C}$ for 20 min under vacuum. The acidity was calculated from the following equation:

$$
\begin{aligned}
& C(\mathrm{~B})=1.88 \mathrm{IA}(\mathrm{B}) R^{2} / W \\
& C(\mathrm{~L})=1.42 \mathrm{IA}(\mathrm{L}) R^{2} / W
\end{aligned}
$$

where $C$ is concentration of $\mathrm{B}$ or $\mathrm{L}$ sites $(\mathrm{mmol} / \mathrm{g})$, IA is the integrated absorbance of $\mathrm{B}$ or $\mathrm{L}$ band $\left(\mathrm{cm}^{-1}\right), R$ is the radius of catalyst disk (cm), and $W$ is the mass of the disk (mg).

\subsection{Catalytic evaluation of metal triflate grafted $S B A-15$ samples}

Catalytic activity of the synthesized ZrTf/S, TiTf/S and AlTf/S samples was evaluated by aminolysis and alcoholysis of the epoxides. The epoxides were reacted with amines or alcohols at defined reaction conditions in the presence of the activated $\left(100^{\circ} \mathrm{C}, 2 \mathrm{~h}\right)$ catalyst samples prepared in this study. The reaction mixtures were analyzed by gas chromatography (Agilent 7890) with a GSBP-5 non-polar column and FID detector for measuring epoxide conversion and product selectivity. The products formed in the reactions were characterized by GC-MS (Agilent 9375MSD with 7890A GC) analysis and the data were matched with those reported in the literature. Conversion of epoxide and product selectivity was calculated from the fol-

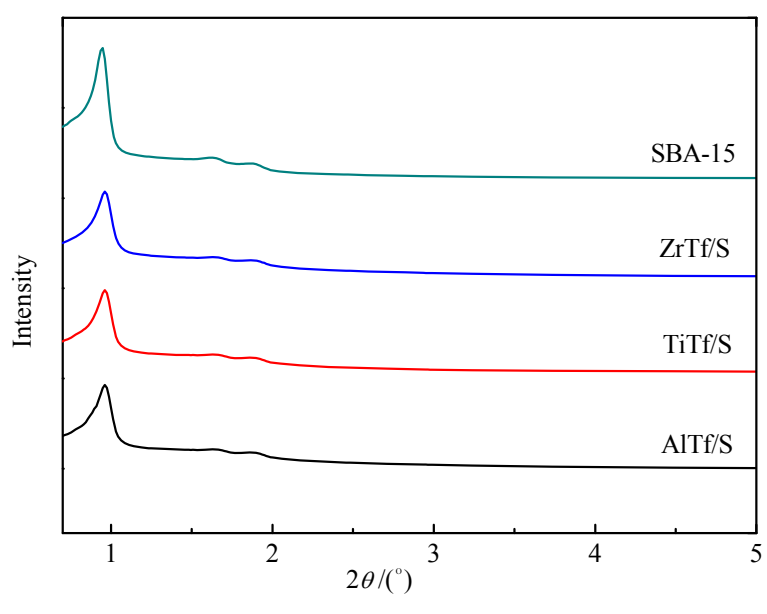

Fig. 1. Powder XRD patterns of SBA-15 and metal triflate grafted on SBA-15 samples.

lowing equations:

Conversion $=($ Initial epoxide mass - final epoxide mass)/Initial epoxide mass $\times 100 \%$

Selectivity for $\mathbf{A}=$ GC Peak area of $\mathbf{A} /$ GC peak area of all the products $\times 100 \%$

Similarly, selectivity for product $\mathbf{B}$ in aminolysis and selectivity for products $\mathbf{C}$ and $\mathbf{D}$ in alcoholysis reactions were calculated.

\section{Results and discussion}

\subsection{Characterization of AlTf/S, TiTf/S, and ZrTf/S samples}

Various physicochemical characterization results are shown in Table 1. Metal (Al, Zr, Ti) content as measured by ICP-AES showed a metal:Si ratio of 1:24.6, 1:26.5, and 1:24.9 for the AlTf/S, TiTf/S, and ZrTf/S samples, respectively (Table 1). The XRD patterns of the SBA-15, ZrTf/S, TiTf/S, and AlTf/S revealed characteristic reflections of a mesoporous structure showing peaks for (100), (110), and (200) planes at low angles indicating that the mesoporous structure of SBA-15 was intact in all the synthesized samples (Fig. 1). A decrease in the intensity of the X-ray reflection was indicative of grafting of the metal triflates. $\mathrm{N}_{2}$-sorption results also revealed a type IV isotherm, and

\begin{tabular}{|c|c|c|c|c|c|c|c|c|}
\hline \multirow{2}{*}{ Material } & \multirow{2}{*}{$\mathrm{S}_{\mathrm{BET}}\left(\mathrm{m}^{2} / \mathrm{g}\right)$} & \multirow{2}{*}{ Pore size $(\mathrm{nm})$} & \multirow{2}{*}{$\begin{array}{l}\text { Pore volume } \\
\left(\mathrm{cm}^{3} / \mathrm{g}\right)\end{array}$} & \multirow{2}{*}{$\mathrm{Si} /$ metal a $^{2}$} & \multicolumn{2}{|c|}{$\mathrm{CF}_{3} \mathrm{SO}_{3}^{-}(\mathrm{mmol} / \mathrm{g})$} & \multirow{2}{*}{$\begin{array}{l}\text { Amount of C by } \\
\text { CHS (mmol/g) }\end{array}$} & \multirow{2}{*}{$\begin{array}{l}\text { Amount of } \\
\text { acidity d }\end{array}$} \\
\hline & & & & & By TGA $^{b}$ & By CHS ${ }^{c}$ & & \\
\hline SBA-15 & 772 & 7.5 & 0.95 & - & - & - & - & - \\
\hline AlTf/S & 575 & 7.6 & 0.75 & 24.6 & 0.58 & 0.53 & - & - \\
\hline TiTf/S & 552 & 7.7 & 0.71 & 26.5 & 0.59 & 0.55 & 0.60 & 0.37 \\
\hline ZrTf/S & 514 & 6.4 & 0.67 & 24.9 & 0.55 & 0.58 & 0.61 & 0.52 \\
\hline
\end{tabular}
a decrease in surface area, pore size, and volume indicate grafting of the metal triflate moiety to the mesoporous structure of SBA-15 (Table 1, Fig. 2). The SBA-15 sample showed the

Table 1

Physicochemical properties of SBA-15, ZrTf/S, TiTf/S, and AlTf/S samples.

a From ICP-AES analysis.

${ }^{\mathrm{b}}$ Calculated from mass loss in TGA in temperature range $230-380{ }^{\circ} \mathrm{C}$.

${ }^{\mathrm{c} C}$ Calculated from $\mathrm{C}, \mathrm{H}, \mathrm{S}$ elemental analysis.

d By FT-IR of pyridine adsorbed samples after desorption at $200{ }^{\circ} \mathrm{C}$ under vacuum $\left(10^{-2} \mathrm{~Pa}\right)$. 


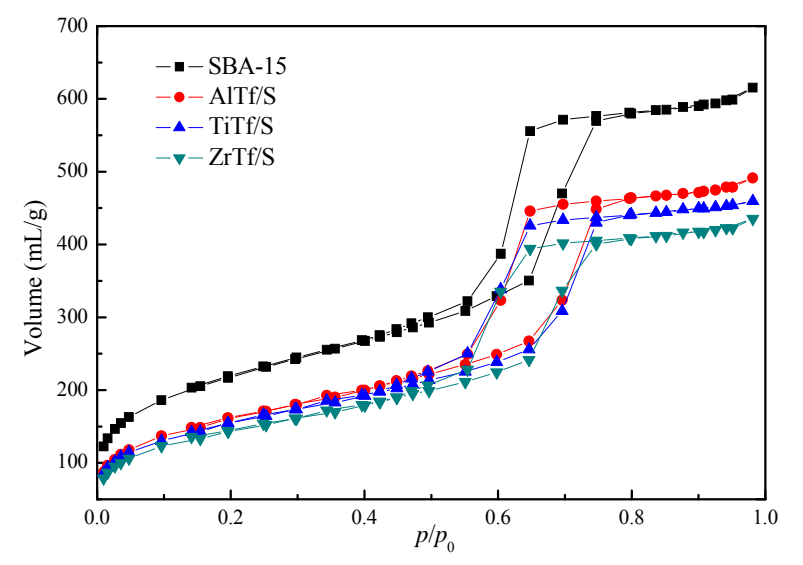

Fig. 2. $\mathrm{N}_{2}$ adsorption-desorption isotherms of SBA-15, ZrTf/S, TiTf/S, and AlTf/S samples.

highest BET surface area of $772 \mathrm{~m}^{2} / \mathrm{g}$, which decreased to 575 , 552, and $514 \mathrm{~m}^{2} / \mathrm{g}$ for the AlTf/S, TiTf/S, and ZrTf/S samples, respectively, after the metal triflate was grated. The TGA analysis results revealed a mass loss of $0.58,0.59$, and $0.55 \mathrm{mmol} / \mathrm{g}$ for the AlTf/S, TiTf/S, and ZrTf/S samples respectively in the temperature range of 230 to $380{ }^{\circ} \mathrm{C}$. This mass loss can be attributed to decomposition of the $\mathrm{CF}_{3} \mathrm{SO}_{3}{ }^{-}$moiety present in the samples (Table 1; Fig. 3). The C, H, S elemental analysis showed the presence of $0.53,0.55$, and $0.58 \mathrm{mmol} / \mathrm{g}$ of the $\mathrm{CF}_{3} \mathrm{SO}_{3}{ }^{-}$ moiety in the AlTf/S, TiTf/S, and ZrTf/S samples, respectively, which is in accordance with the TGA results (Table 1). The amount of $\mathrm{C}$ detected in the samples was consistent with the amount of triflate added during synthesis and suggested nearly complete reaction of the alkoxide metal precursor with triflic acid and the silica surface. The FT-IR spectra of these synthesized samples also showed characteristic absorption bands at $\sim 580$ and $\sim 645 \mathrm{~cm}^{-1}$ attributed to the $-\mathrm{CF}_{3}$ asymmetric deformation and $\mathrm{SO}_{3}$ symmetric deformation vibrations, respectively (Fig. 4) [33-35]. A very weak band observed at $\sim 760$ $\mathrm{cm}^{-1}$ was attributed to $\mathrm{C}-\mathrm{S}$ stretching vibrations. IR bands at $\sim 1290$ and $1030 \mathrm{~cm}^{-1}$ were attributed to $S=0$ stretching vibrations, which were observed as a shoulder in all samples (except SBA-15) merged with the characteristic Si-O-Si bands of silica in the same region [7,33-35]. The strong and broad band between 3600 and $3200 \mathrm{~cm}^{-1}$ was attributed to $\mathrm{O}-\mathrm{H}$ stretching

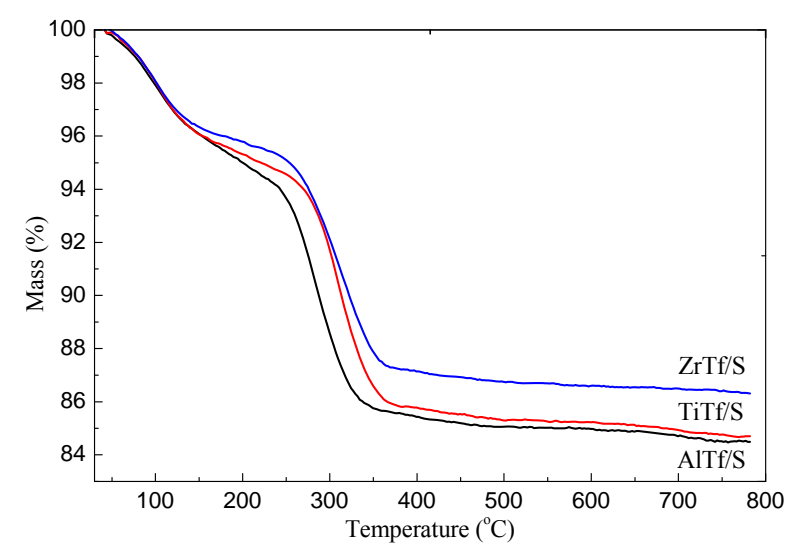

Fig. 3. TGA plots of synthesized ZrTf/S, TiTf/S, and AlTf/S samples.

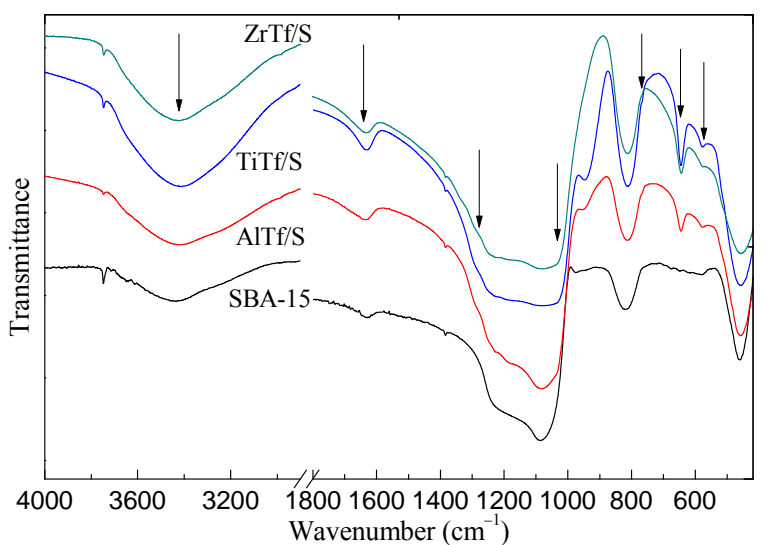

Fig. 4. FT-IR spectra of SBA-15, AlTf/S, TiTf/S, and ZrTf/S samples.

and that at $\sim 1650 \mathrm{~cm}^{-1}$ was attributed to bending vibrations of water molecules associated with surface silanol groups. These characterization results confirmed the successful grafting of the metal triflates onto the SBA-15 mesoporous surface. Thus, it is likely that our one-pot-two-step metal triflate-grafting approach may be extended to other metal triflates [31].

The FT-IR spectrum measured after in-situ pyridine adsorption under vacuum showed bands at 1546 and $1640 \mathrm{~cm}^{-1}$, which were assigned to the pyridinium ions adsorbed at $\mathrm{B}$ sites. Bands at 1450 and $1610 \mathrm{~cm}^{-1}$ were assigned to pyridine adsorbed at $\mathrm{L}$ acid sites and a further band at $1490 \mathrm{~cm}^{-1}$ was assigned to pyridine adsorbed to both $\mathrm{B}$ and $\mathrm{L}$ acid $(\mathrm{B}+\mathrm{L})$ sites (Fig. 5) [36-38]. The greatest acidity was observed for ZrTf/S (0.52 mmol/g) (Table 1) while TiTf/S and AlTf/S showed slightly lower acidity ( 0.37 and $0.34 \mathrm{mmol} / \mathrm{g}$, respectively). The acidity reduced gradually with increasing desorption temperature; however, even after desorption at $200{ }^{\circ} \mathrm{C}$ the samples continued to show moderate strength and high acidity. UV-vis diffuse reflectance spectra revealed metal-ligand $\left(\mathrm{O}^{2-}\right.$ and $\mathrm{CF}_{3} \mathrm{SO}_{3}{ }^{-}$) charge transfer interactions of the metal in the ZrTf/S, TiTf/S, and AlTf/S samples (Fig. 6) [39-41]. The peak at $\sim 220$ $\mathrm{nm}$ indicated the presence of tetrahedral coordinated metal centers $\left(\mathrm{CF}_{3} \mathrm{SO}_{3}-\mathrm{M}-(\mathrm{O}-\mathrm{Si})_{3} ; \mathrm{M}=\mathrm{Zr}, \mathrm{Ti}, \mathrm{Al}\right)$. The broad absorption band observed in all samples from around 260 to $300 \mathrm{~nm}$ could be assigned to octahedral and pentahedral coordinated metal centers generated from interactions with neighboring

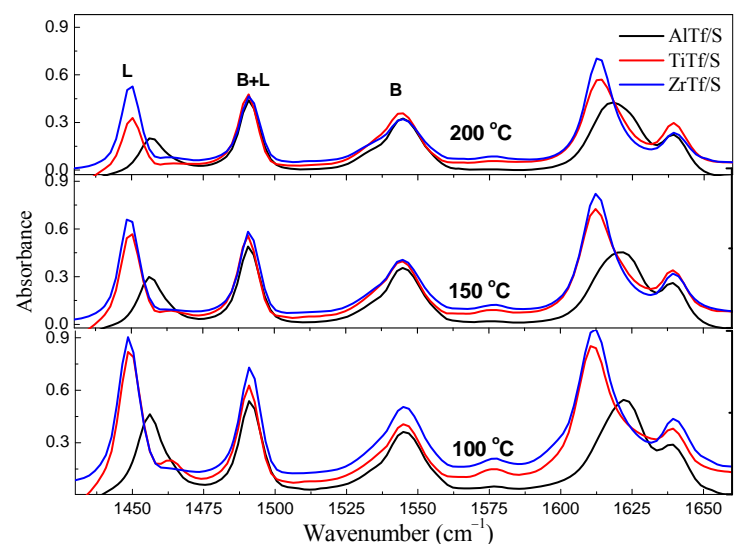

Fig. 5. FT-IR spectra of pyridine adsorbed ZrTf/S, TiTf/S, and AlTf/S samples indicating $\mathrm{L}$ and $\mathrm{B}$ acidic sites. 


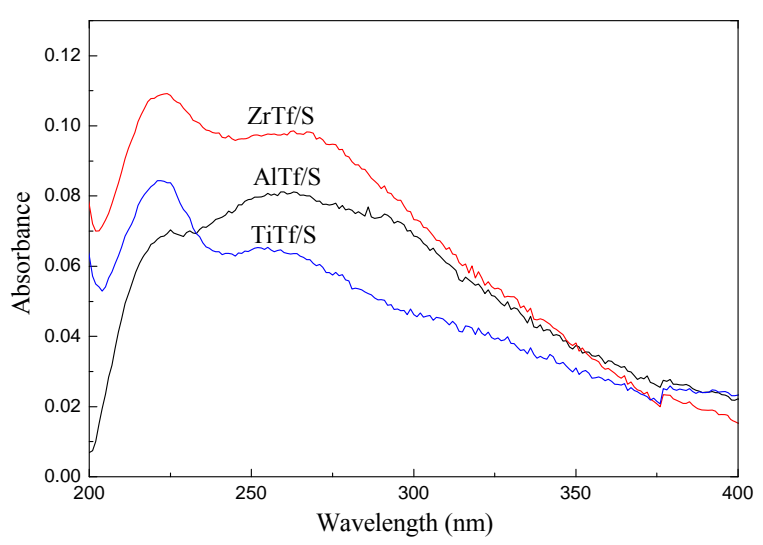

Fig. 6. Diffuse reflectance UV-visible spectra of ZrTf/S, TiTf/S, and AlTf/S samples.

hydroxyl groups, as shown in Scheme 1.

\subsection{Catalytic evaluation of metal triflate grafted on SBA-15 samples for epoxide ring opening reaction}

\subsubsection{Reaction condition optimization}

For optimization of reaction conditions (Table 2), we initially reacted styrene oxide with aniline in a $25-\mathrm{mL}$ round bottom flask at $25^{\circ} \mathrm{C}$ in acetonitrile as a solvent in the presence of $25 \mathrm{mg}$ of the activated $\left(100^{\circ} \mathrm{C}, 2 \mathrm{~h}\right) \mathrm{ZrTf} / \mathrm{S}$ sample. These conditions produced $52 \%$ conversion of the epoxide and $95 \%$ selectivity for the desired $\beta$-amino alcohol products $(\mathbf{A}+\mathbf{B})$ at 25 ${ }^{\circ} \mathrm{C}$. A similar reaction was performed in toluene and under conditions with no solvent. Under these reaction conditions $71 \%$ conversion and $94 \%$ selectivity was observed in toluene, while the reaction without solvent afforded 91\% conversion of the epoxide with $95 \%$ selectivity. At $35{ }^{\circ} \mathrm{C}$ we achieved an even higher conversion of $94 \%$ with $96 \%$ selectivity. Thus, the catalytic performance of the ZrTf/S sample was better under solvent free conditions, which can be explained by the fact that dilution of the reaction mixture in the solvent assisted reaction

\section{Table 2}

Reaction condition optimization for epoxide ring opening of styrene oxide with aniline and with methanol catalyzed by ZrTf/S (25 mg) a.

\begin{tabular}{lcccc}
\hline Entry & $\begin{array}{c}\text { Temp./Time } \\
\left({ }^{\circ} \mathrm{C} / \mathrm{min}\right)\end{array}$ & Solvent & $\begin{array}{c}\text { Epoxide } \\
\text { conversion }(\%)\end{array}$ & $\begin{array}{c}\text { Selectivity } \\
(\%)\end{array}$ \\
\hline 1 & $25 / 30$ & acetonitrile & 52 & 95 \\
2 & $25 / 30$ & toluene & 71 & 94 \\
3 & $25 / 30$ & - & 91 & 95 \\
4 & $35 / 30$ & - & 94 & 96 \\
$5\left(1^{\text {st }}\right.$ recycle $)$ & $35 / 30$ & - & 95 & 97 \\
$6\left(2^{\text {nd }}\right.$ recycle $)$ & $35 / 30$ & - & 93 & 96 \\
$7\left(3^{\text {rd }}\right.$ recycle $)$ & $35 / 30$ & - & 93 & 96 \\
$8\left(4^{\text {th }}\right.$ recycle $)$ & $35 / 30$ & - & 94 & 95 \\
9 & $35 / 10$ & - & 100 & 98 \\
$10\left(1^{\text {st }}\right.$ recycle $)$ & $35 / 10$ & - & 98 & 96 \\
$11\left(2^{\text {nd }}\right.$ recycle $)$ & $35 / 10$ & - & 99 & 95 \\
$12\left(3^{\text {rd }}\right.$ recycle $)$ & $35 / 10$ & - & 100 & 99 \\
$13\left(4^{\text {th }}\right.$ recycle $)$ & $35 / 10$ & - & 98 & 96 \\
\hline
\end{tabular}

aEntries 1-8: Styrene oxide (5 mmol), aniline (5 mmol); selectivity for $(\mathbf{A}+\mathbf{B})$.

Entries 9-13: Styrene oxide (2 mmol), methanol (25 mmol); selectivity for $(\mathbf{C}+\mathbf{D})$.

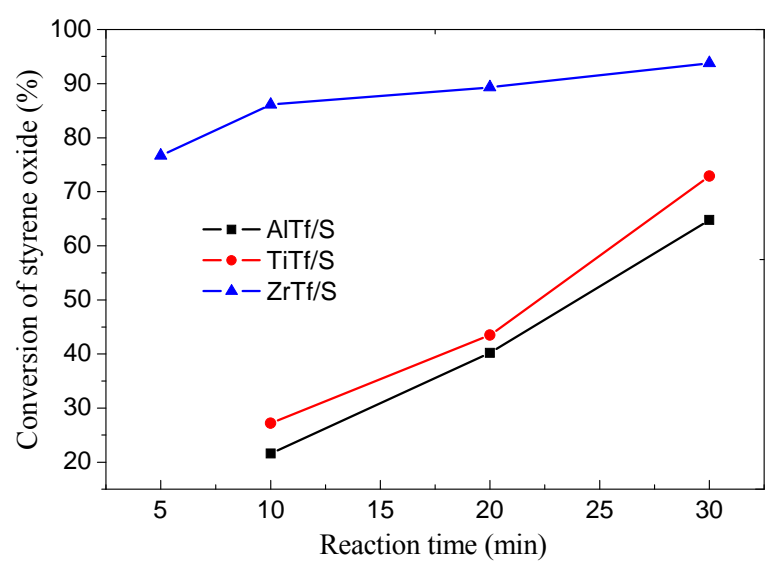

Fig. 7. Comparison of catalytic activity of synthesized samples for epoxide ring opening of styrene oxide by aniline. Reaction conditions: styrene oxide ( $5 \mathrm{mmol})$, aniline $(5 \mathrm{mmol})$, catalyst $(25 \mathrm{mg}), 35^{\circ} \mathrm{C}$.

may reduce the product formation rate (Table 2). The solvent had no significant effect on the selectivity of the products. The reusability of the ZrTf/S sample was evaluated for four reaction cycles. In the reusability study for aminolysis, the reaction mixture was filtered after completion of the reaction to separate the used ZrTf/S. The used ZrTf/S sample was washed with petroleum ether and activated at $100{ }^{\circ} \mathrm{C}$ for $2 \mathrm{~h}$ before the next reaction cycle. In the aminolysis reaction, conversion of styrene oxide and selectivity for the $\beta$-amino alcohol were unaffected ( $94 \%$ and $95 \%$, respectively) after four cycles. For a reusability study of alcoholysis, the reaction mixture was filtered after completion of the reaction to separate the used ZrTf/S catalyst. The ZrTf/S sample was directly activated at $100{ }^{\circ} \mathrm{C}$ for $2 \mathrm{~h}$ before the next reaction cycle. The activity of ZrTf/S was also unaffected after recycling for the alcoholysis reaction up to four reaction cycles (98\% conversion of styrene oxide and 96\% selectivity for $\beta$-alkoxy alcohol (C+D)).

The catalytic activity of the AlTf/S, TiTf/S, and ZrTf/S samples was compared for the ring opening of styrene oxide with aniline (Fig. 7). The ZrTf/S sample clearly showed the highest activity for this reaction giving 94\% conversion of the epoxide in $30 \mathrm{~min}$, while the selectivity of all the samples was comparable ( $>96 \%$ ). The highest activity of ZrTf/S may be attributed to its stronger Lewis acidity $(0.52 \mathrm{mmol} / \mathrm{g})$ than those of the TiTf/S and AlTf/S catalysts (Fig. 5).

\subsubsection{Aminolysis of epoxides with amines over $\mathrm{ZrTf} / \mathrm{S}$}

Various epoxides were then reacted with amines in the presence of the ZrTf/S sample at $35{ }^{\circ} \mathrm{C}$ and at an equimolar ratio to explore the substrate scope (Table 3). Styrene oxide reacted with aniline very efficiently to produce $\beta$-amino alcohol with $94 \%$ conversion of styrene oxide and $91 \%$ selectivity for isomer A and 96\% total selectivity for (A+B) in 0.5 h. Cyclohexene oxide reacted with aniline to selectively produce the $\beta$-amino alcohol with $89 \%$ conversion of the epoxide in $1 \mathrm{~h}$. The reactivity of styrene oxide was much higher than that of cyclohexene oxide because the intermediate carbocation formed from styrene oxide is stabilized by resonance with the aromatic ring and is highly susceptible to nucleophilic attack (Scheme 3). 
Table 3

Aminolysis of epoxides with different amines using ZrTf/S $(25 \mathrm{mg})$ at $35^{\circ} \mathrm{C}^{\mathrm{a}}$.

Epoxide
Entry

${ }^{a}$ Entries 2-6: product selectivity includes both stereoisomers (trans- and cis-) and is calculated form GC.

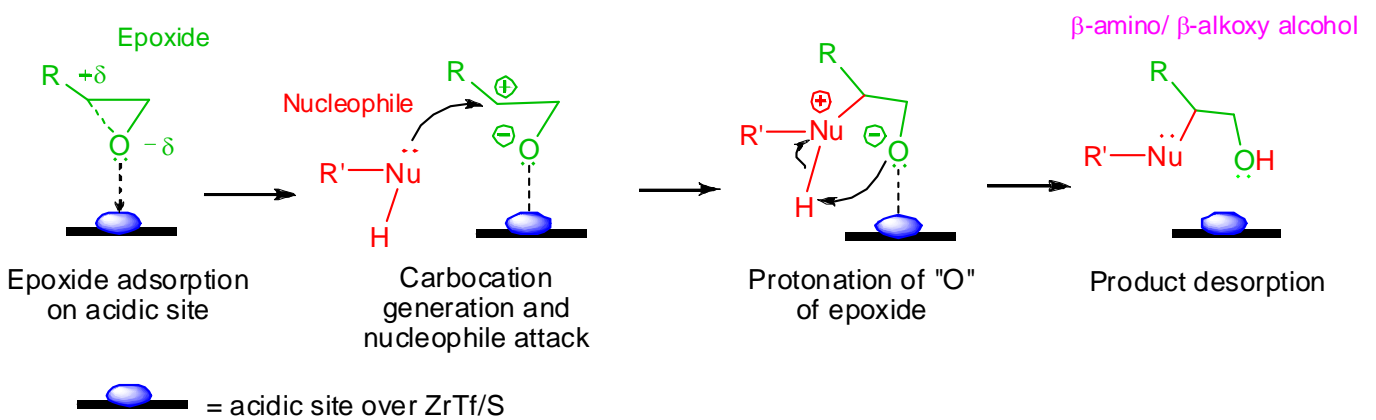

Scheme 3. Plausible reaction pathway of epoxide ring opening reaction over ZrTf/S.

Similarly, the effect of nucleophilicity of the amine was observed in the reaction of cyclohexene oxide with $p-\mathrm{Cl}, p-\mathrm{CH}_{3}$, and $p-\mathrm{OCH}_{3}$ aniline, which afforded $88 \%, 79 \%$, and $78 \%$ conversion with $97 \%, 99 \%$, and $99 \%$ selectivity, respectively (Table 3). Cyclohexene oxide also reacted with cyclohexyl amine giving $12 \%$ conversion and $83 \%$ selectivity after $5 \mathrm{~h}$ at $45^{\circ} \mathrm{C}$. The low conversion may be explained by the strong adsorption of the aliphatic amine to acidic sites of ZrTf/S, which caused poisoning of the active sites and lowered product formation. Styrene oxide with cyclohexyl amine also gave reduced product conversion (19\%) owing to a similar effect (Table 3). These results demonstrate the excellent activity of the catalyst, even in the presence of highly basic amines. Epichlorhydrin, allylglycidyl ether, and phenyl glycidyl ether also reacted with aniline affording $100 \%, 86 \%$, and $97 \%$ epoxide conversion with $80 \%, 79 \%$, and $88 \%$ selectivity for product isomer $\mathbf{A}$, and
$90 \%, 91 \%$, and $94 \%$ total selectivity for $(\mathbf{A}+\mathbf{B})$.

\subsubsection{Alcoholysis of epoxides with alcohols}

The ZrTf/S sample also catalyzed epoxide ring opening with various alcohols efficiently at $35{ }^{\circ} \mathrm{C}$ (Table 4). Initially, cyclohexene oxide was reacted with methanol in an equimolar ratio $(1: 1,5 \mathrm{mmol})$, which resulted in $100 \%$ conversion of epoxide but only $73 \%$ selectivity for the desired product. At higher molar ratios of cyclohexene oxide to methanol (2:25 and 2:50), a very high selectivity for the desired product (96\% and 98\%) was achieved within $10 \mathrm{~min}$ (Table 4). Styrene oxide reacted with methanol to give $100 \%$ conversion and $95 \%$ selectivity to 2-methoxy-2-phenylethanol (product isomer C) at a 2:25 molar ratio in $10 \mathrm{~min}$. Although these conditions gave complete conversion, only $66 \%$ selectivity for product isomer C was achieved at an equimolar ratio. The by-product formed was 
Table 4

Alcoholysis of epoxides with different alcohols catalyzed by ZrTf/S (25 mg) at $35{ }^{\circ} \mathrm{Ca}$.

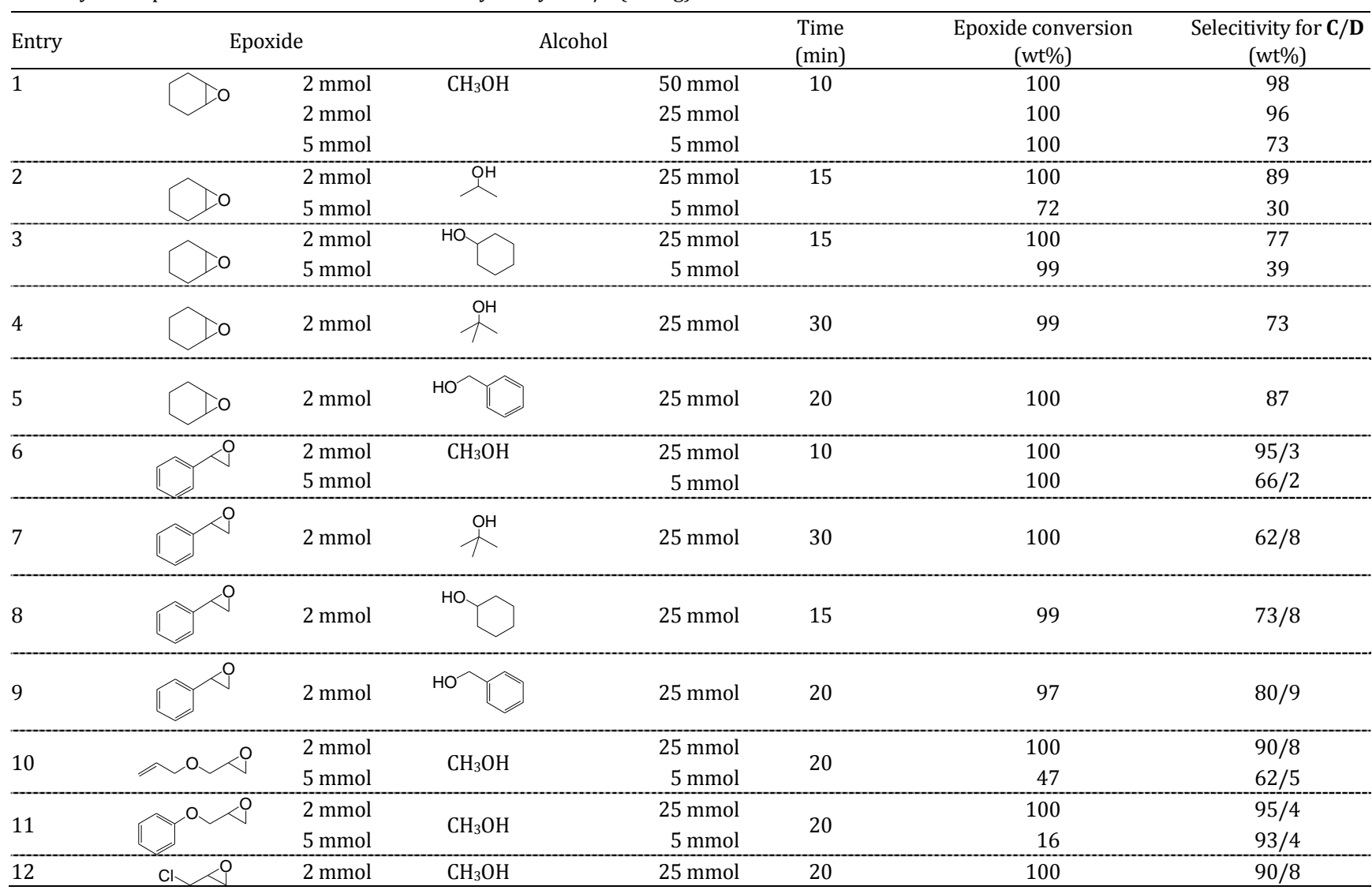

a Entries 1-5: Product selectivity includes both stereoisomers (trans- and cis-) and is calculated form GC.

predominantly the acid catalyzed Meinwald rearrangement product [10] (phenylacetaldehyde), which also highlights the acidic nature of the catalytic sites on the ZrTf/S sample. Secondary, tertiary, and benzylic alcohols also reacted with cyclohexene oxide as well as styrene oxide, to give complete conversion and excellent selectivity at a 2:25 ratio of epoxide to alcohol. Cyclohexene oxide reacted completely with $i$-propanol and cyclohexanol giving $89 \%$ and $77 \%$ selectivity in 15 min. Similarly, $t$-butanol and benzyl alcohol also reacted with cyclohexene oxide with $73 \%$ and $87 \%$ selectivity in 20 and $30 \mathrm{~min}$, respectively (Table 4). Styrene oxide reacted with $t$-butanol, benzylalcohol, and cyclohexanol giving $62 \%, 73 \%$, and $80 \%$ selectivity for product isomer $\mathbf{C}$ and $70 \%, 81 \%$, and $89 \%$ selectivity for $(\mathbf{C}+\mathbf{D})$, respectively, with nearly complete conversion. Such remarkable catalytic activity at low epoxide to alcohol molar ratios and at ambient reaction conditions makes our ZrTf/S catalyst stand out from previously reported Cu-MOF [9], mesoporous aluminosilicate [10], $\mathrm{Fe}(\mathrm{BTC})$ [11], $\mathrm{CuO} / \mathrm{SiO}_{2}$ [12], and sulfonic acid functionalized mesoporous carbon [14] based catalysts. Similarly, epichlorohydrin, allylglycidyl ether and phenyl glycidyl ether reacted with methanol affording excellent conversion (100\%) and 90\%, 90\%, and 95\% selectivity for product isomer $\mathbf{C}$ and $98 \%, 99 \%$, and $98 \%$ selectivity for (C+D) in $20 \mathrm{~min}$.

\subsubsection{Plausible reaction pathway}

When the epoxide molecule adsorbs to the ZrTf/S catalyst, acidic site is activated, which induces polarization causing electron deficiency on the highest substituted carbon of the epoxide ring (Scheme 3). The nucleophile (amine/alcohol) then attacks this electron deficient carbon followed by protonation of the epoxide $\mathrm{O}$ by a proton from the nucleophile to ultimately form the final product $\beta$-amino/ $\beta$-alkoxy alcohol.

\section{Conclusions}

We have successfully demonstrated a general one-pot- twostep method for synthesis of metal triflate grafted mesoporous silica catalyst. The ZrTf/S catalyst prepared in the study was found to be easily synthesized, reusable and highly efficient for catalysis of epoxide ring opening by alcohols and amines. The ZrTf/S sample showed higher catalytic activity than the AlTf/S and TiTf/S samples owing to its higher acidity. Furthermore, high catalytic activity for epoxide ring opening with poor nucleophiles was obtained.

\section{Acknowledgments}

Authors are thankful to Chinese Academy of Sciences (CAS) and Dalian Institute of Chemical Physics, CAS for providing financial support and CAS President's International Fellowship Initiative funding. 


\section{Graphical Abstract}

Chin. J. Catal., 2017, 38: 758-766 doi: 10.1016/S1872-2067(17)62794-3

Zirconium triflate grafted on SBA-15 as a highly efficient solid acid catalyst for ring opening of epoxides by amines and alcohols

Kamlesh N. Tayade, Lianyue Wang, Sensen Shang, Wen Dai, Manish Mishra, Shuang Gao *

Dalian Institute of Chemical Physics, Chinese Academy of Sciences, China; Dharmsinh Desai University, India

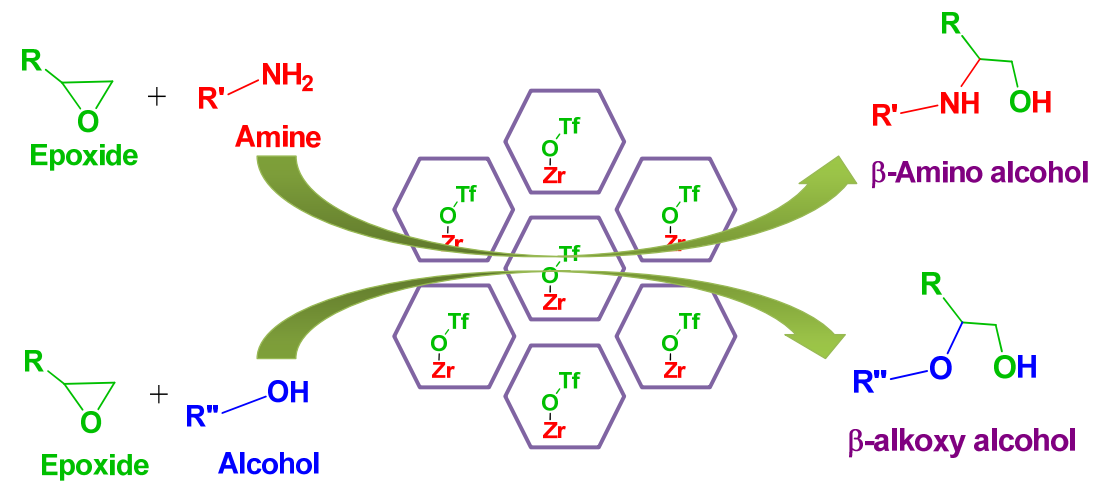

We report the synthesis of zirconium triflate grafted mesoporous SBA-15 (ZrTf/S) using a simple one-pot-two-step synthesis. ZrTf/S showed excellent activity for ring opening of epoxides by various amines and alcohols under ambient conditions.

\section{References}

[1] O. Mitsunobu, in: E. Winterfeldt (ed.), Comprehensive Organic Synthesis, Pergamon Press, New York, 1996, Part 1.3.4.1.

[2] D. J. Ager, I. Prakash, D. R. Schaad, Chem. Rev.,1996, 96, 835-876.

[3] E. J. Corey, F. Y. Zhang, Angew. Chem. Int. Ed., 1999, 38, 1931-1934.

[4] P. O'Brien, Angew. Chem. Int. Ed., 1999, 38, 326-329.

[5] G. G. Li, H. T. Chang, K. B. Sharpless, Angew. Chem. Int. Ed., 1996, 35, 451-454.

[6] C. Baylon, G. Prestat, M. P. Heck, C. Mioskowski, Tetrahedron Lett., 2000, 41, 3833-3835.

[7] L. Saikia, J. K. Satyarthi, D. Srinivas, P. Ratnasamy, J. Catal., 2007, 252, 148-160.

[8] R. I. Kureshy, S. Singh, N. H. Khana, S. H. R. Abdi, E. Suresh, R. V. Jasra, J. Mol. Catal. A, 2007, 264, 162-169.

[9] D. Jiang, T. Mallat, F. Krumeich, A. Baiker, J. Catal., 2008, 257, 390-395.

[10] M. W. C. Robinson, A. M. Davies, R. Buckle, I. Mabbett, S. H. Taylor, A. E. Graham, Org. Biomol. Chem., 2009, 7, 2559-2564.

[11] A. Dhakshinamoorthy, M. Alvaro, H. Garcia, Chem. Eur. J., 2010, 16, 8530-8536.

[12] F. Zaccheria, F. Santoro, R. Psaro, N. Ravasio, Green Chem., 2011, 13, 545-548.

[13] A. Kumar, D. Srinivas, J. Catal., 2012, 293, 126-140.

[14] I. Matos, P. D. Neves, J. E. Castanheiro, E. Perez-Mayoral, R. Martin-Aranda, C. Duran-Valle, J. Vital, A. M. Botelho do Rego, I. M. Fonseca, Appl. Catal. A, 2012, 439-440, 24-30.

[15] M. Mirza-Aghayan, M. Alizadeh, M. Molaee. Tavana, R. Boukherroub, Tetrahedron Lett., 2014, 55, 6694-6697.

[16] B. Tang, W. L. Dai, X. M. Sun, G. J. Wu, N. J. Guan, M. Hunger, L. D. Li, Green Chem., 2015, 17, 1744-1755.
[17] S. Kobayashi, M. Sugiura, H. Kitagawa, W. W. L. Lam, Chem. Rev., 2002, 102, 2227-2302.

[18] S. Kobayashi, K. Manabe, Acc. Chem. Res., 2002, 35, 209-217.

[19] S. Kobayashi, Eur. J. Org. Chem., 1999, 15-27.

[20] A. Kawada, S. Mitamura, S. Kobayashi, J. Chem. Soc., Chem. Commun., 1993, 1157-1158.

[21] A. Kawada, S. Mitamura, S. Kobayashi, Chem. Commun., 1996, 183-184.

[22] G. A. Olah, O. Farooq, S. M. F. Farnia, J. A. Olah, J. Am. Chem. Soc., 1988, 110, 2560-2565.

[23] V. Sage, J. H. Clark, D. J. Macquarrie, J. Catal., 2004, 227, 502-511.

[24] V. Sage, J. H. Clark, D. J. Macquarrie, J. Mol. Catal. A, 2003, 198, 349-358.

[25] K. Mantri, K. Komura, Y. Kubota, Y. Sugi, J. Mol. Catal. A, 2005, 236, 168-175.

[26] T. Kawabata, T. Mizugaki, K. Ebitani, K. Kaneda, J. Am. Chem. Soc., 2003, 125, 10486-10487.

[27] C. Wiles, P. Watts, ChemSusChem, 2012, 5, 332-338.

[28] S. Kobayashi, S. Nagayama, J. Org. Chem., 1996, 61, 2256-2257.

[29] W. Q. Gu, W. J. Zhou, D. L. Gin, Chem. Mater., 2001, 13, 1949-1951.

[30] B. M. Choudary, C. Sridhar, M. Sateesh, B. Sreedhar, J. Mol. Catal. A, 2004, 212, 237-243.

[31] K. N. Tayade, M. Mishra, K. Munusamy, R. S. Somani, Catal. Sci. Technol., 2015, 5, 2427-2440.

[32] A. Y. Khodakov, V. L. Zholobenko, R. Bechara, D. Durand, Microporous Mesoporous Mater., 2005, 79, 29-39.

[33] M. Chidambaram, C. Venkatesan, P. R. Rajamohanan, A. P. Singh, Appl. Catal. A, 2003, 244, 27-37.

[34] S. Selvakumar, N. M. Gupta, A. P. Singh, Appl. Catal. A, 2010, 372, 130-137.

[35] D. H. Johnston, D. F. Shriver, Inorg. Chem., 1993, 32, 1045-1047.

[36] A. Corma, V. Fornes, M. T. Navarro, J. Perez-pariente, J. Catal., 1994, 148, 569-574. 
[37] R. Mokaya, W. Jones, Z. Luan, M. D. Alba, J. Klinowski, Catal. Lett., 1996, 37, 113-120.

[38] A. Corma, Chem. Rev., 1995, 95, 559-614.

[39] A. Ramanathan, M. C. Castro Villalobos, C. Kwakernaak, S.
Telalovic, U. Hanefeld, Chem. Eur. J., 2008, 14, $961-972$.

[40] S. Y. Chen, J. F. Lee, S. Cheng, J. Catal., 2010, 270, 196-205.

[41] R. Peng, D. Zhao, N. M. Dimitrijevic, T. Rajh, R. T. Koodali, J. Phys. Chem. C, 2012, 116, 1605-1613.

\section{高效固体酸SBA-15-Zr(OTf) 3 催化胺或醇开环环氧化合物}

Kamlesh N. Tayade ${ }^{\mathrm{a}}$, 王连月 ${ }^{\mathrm{a}}$, 尚森森 ${ }^{\mathrm{a}}$, 戴 文 ${ }^{\mathrm{a}}$, Manish Mishra ${ }^{\mathrm{b}}$, 高 爽, ${ }^{\mathrm{a}}$,

a中国科学院大连化学物理研究所洁净能源国家实验室(筹), 辽宁大连 116023

b德赛大学技术学院化学工程系, Shah-Schulman表面科学与纳米技术中心, 古吉拉特邦, 纳迪亚德市, 印度

摘要: 通过简单的一锅两步法制备了三氟金属(铝, 钣, 锆)接枝介孔SBA-15 (AlTf/S, TiTf/S, ZrTf/S)固体酸材料, 并通过XRD, $\mathrm{N}_{2}$ 吸附, TGA, FTIR, 原位吡啶FTIR和元素分析对这些材料进行了详细的表征. 其中, ZrTf/S能够高效催化环氧化物温和条件 下被胺或醇开环生成对应 $\beta$-氨基醇或 $\beta$-烷氧基醇, 并且催化剂能循环利用. ZrTf/S相较于AlTf/S和TiTf/S酸性最强, 因而催化 活性也最高.

关键词: 环氧开环; 酸催化; 三氟金属; 接枝催化剂; 介孔硅

收稿日期: 2016-11-21. 接受日期: 2017-01-06. 出版日期: 2017-04-05.

*通讯联系人. 电话/传真: (0411)84379728; 电子信箱: sgao@dicp.ac.cn

基金来源：中国科学院国际人才计划(2016PT028)、国家自然科学基金(21273225、21403219).

本文的英文电子版由Elsevier出版社在ScienceDirect上出版(http://www.sciencedirect.com/science/journal/18722067). 